\title{
Functional Requirements Analysis on Construction Project Cost System
}

\author{
Nannan Zhang ${ }^{1, a}$, Jingzhao Luan ${ }^{2, b}$ \\ ${ }^{1}$ School of Management, Bohai University, Jinzhou, 121013, China \\ ${ }^{2}$ State Grid Dalian Electric Power Supply Company, Dalian, 116001, China \\ a331263907@qq.com, b13889588669@139.com
}

Keywords: construction project; cost system; system function; requirement analysis; cost composition; use case model; functional framework

\begin{abstract}
Construction project cost is the key problem in the control and management of construction project. For the existing cost system can not adapt to the development of the construction industry information needs of the status, this paper based on the use case model technology to the construction cost system function demand analysis, provides support for the system development. The research content is based on the construction cost structure, and design the use case model of construction cost system, design the construction project cost system function frame. The core function of the system is composed of "Template information management, Supplier information management, Cost model management, Project cost management, Cost control management, System maintenance management" six modules, each of which contains a number of sub modules. In this paper, the design method is reliable, and the function design is comprehensive.
\end{abstract}

\section{Introduction}

In software engineering, demand analysis refers to the establishment of a new or change an existing system, descript new system's purpose, scope, definition and function of all work, is a key process in software engineering. In this process, the system analyst and software engineer determine the user needs. Only after identifying these needs, be able to analyze and seek solutions to the new system. In the demand analysis stage, must be detailed analysis to solve the problem, clarify the requirements of the problem, including the need to enter any data, get what results, and what should be finally output. Analysis of software system functional requirements, performance requirements, reliability and availability requirements, error processing needs, interface requirements, constraints, needs of reverse, which may be in the future requirements was described. Functional requirement is a basic requirement of software system, and it is also the most important task of requirement analysis.

With the rapid development of China's reform and opening up of the market economy, construction investment enterprises in the face of good opportunities, but also faces of severe market challenges. Industry market competition trend gradually show, the need for construction investment practitioners in order to improve decision-making ability, reduce risk and improve work efficiency, have used the project cost system. But currently widely used in the fields of engineering cost system exists a serious problem, for example, generic versions of the poor, the standard is not unified, basic data input cumbersome, response speed is slow, long treatment period and efficiency low inferior. Such a cost system, the accuracy is not high, can not meet the needs of the construction industry information. Therefore, explore and study the adaptation new construction market situation and the project cost system is an urgent need to address the problem, meet the needs of the rapid development of the construction industry, support the decision of investment managers. In this paper, the function of building engineering cost system needs analysis, provide support for the development of the system.

\section{Cost Composition on Construction Project}

The cost of construction products is composed of direct cost and indirect cost, which is the monetary expression of living labor and materialized labor in the process of building production. 
Construction product cost reflects the cost of construction enterprises in the production and sale of building products in the process of spending, the focus reflects the economic results of all the work of the enterprise. Building products price is the monetary expression of the value of building products, product prices are costs of labor to create products in the production process, and gain profit, so construction project cost by the Ministry of the direct costs, indirect costs, profits and taxes four components and specific composition as shown in Fig. 1 [1-3].

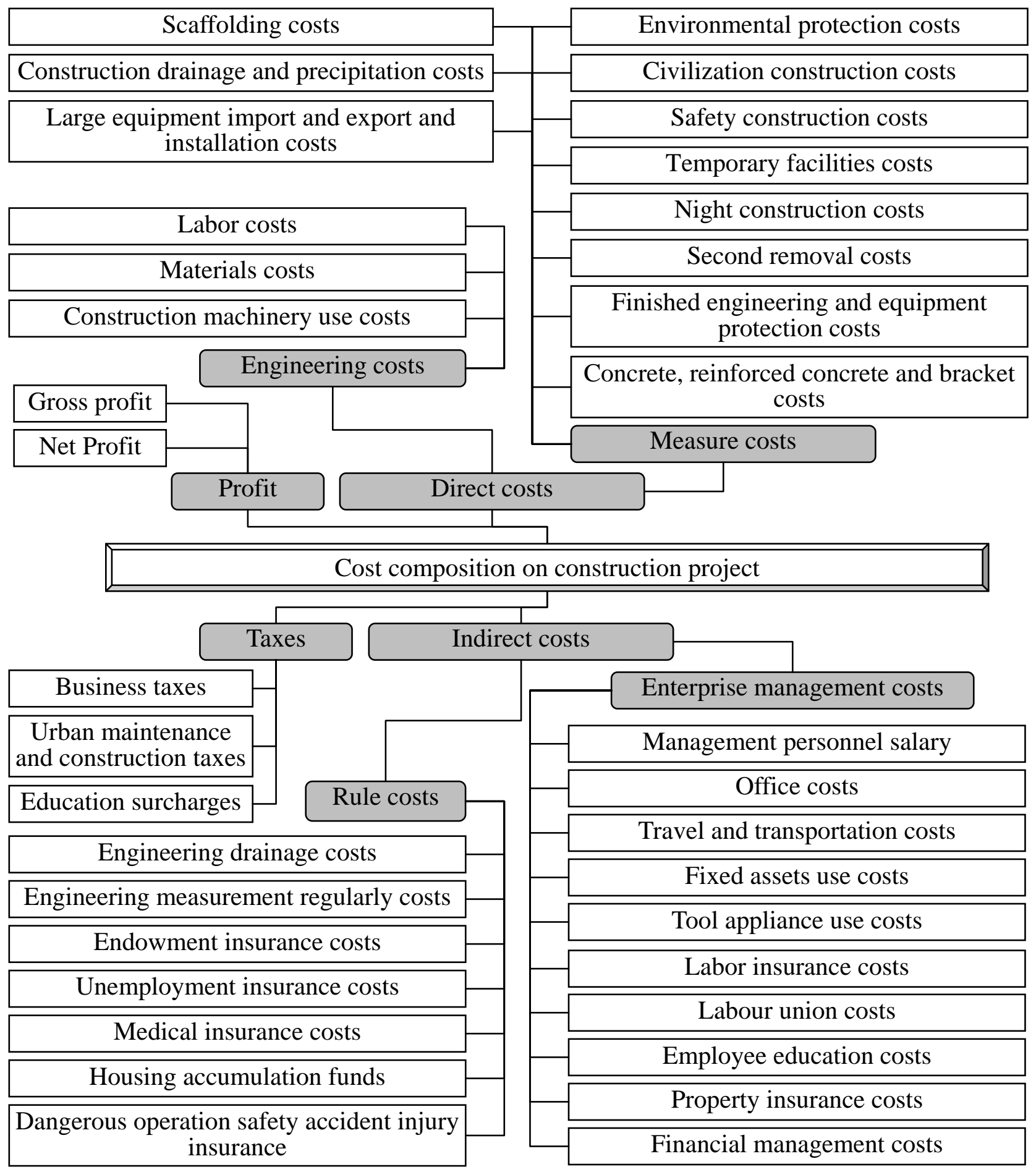

Fig. 1. Cost composition on construction project

Direct costs arising from the implementation of construction projects, is mainly refers to able to complete the project construction cost, including two types of engineering cost and measures cost; indirect costs occurred in the construction process, mainly related to the management of wages, also includes the cost of travel management personnel and fixed assets; Profit is an important part of the construction project cost, profit is the firms decide whether to carry out the key factors in the 
construction project, also is the enterprise further development and expansion of the main indicators; construction and installation engineering, enterprises should according to the relevant provisions of the state to the Ministry of finance tax, so as to ensure that national finance income, it is the obligation that the enterprise should do.

\section{Use Case Model on Construction Project Cost System}

Unified modeling language (UML), provides modeling and visualization support for all stages of software development.UML have three main model in the system development, respectively, function model, from the user's point of view display system function, including the use case diagram; the concept of object model, the objects, attributes, operations, and related display system of structure and foundation, including class diagram; dynamic models show the internal behavior of the system, including the sequence diagram, activity diagram and state diagram $[4,5]$. Use case view is considered to play a dominant role in the UML, describe the system's external visual behavior. In the case of software development considering the requirement of the system, the use case diagram determines the driving force and the development of the subsequent development. The system use case model is shown in Fig. 2.

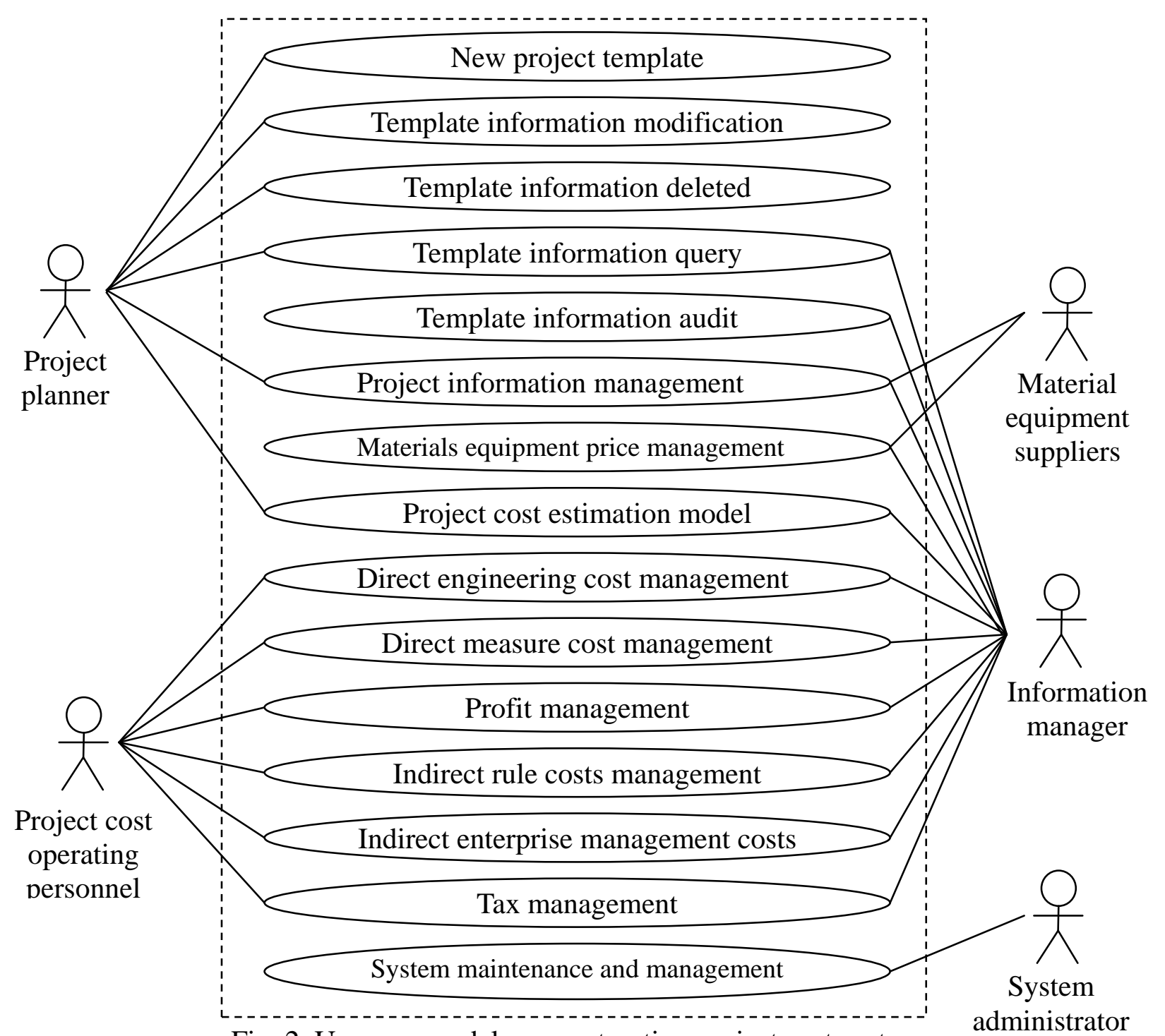

Fig. 2. Use case model on construction project cost system

In the use case model shown in Fig. 2, including five categories of users, respectively, project planner, project cost operating personnel, material equipment suppliers, Information manager, system administrator. Among them, planner project, is a senior technical personnel of enterprises, mainly responsible for the template and engineering cost template management; project cost 
operating personnel, is the general staff of the enterprise, according to the project cost template to complete the construction project cost estimation; material equipment suppliers, is the enterprise's external personnel, you can query the enterprise's project information, and provide information to the enterprise equipment pricing information; information manage, is the general information management and management of enterprises, maintain or query the relevant information Is the general information management and management of enterprises, to maintain or query the relevant information, system administrator, is the system administrator, in order to maintain the normal operation of the system to the system.

\section{Functional Framework on Construction Project Cost System}

Function frame structure is the result of simulation, the function of the system is decomposed, according to the function of the relationship between the figure, the figure of each rectangle is called a function module. Each subsystem of the management information system can be regarded as the function of the lower level of the system, and the function of each subsystem can be further decomposed into more functions. Functional decomposition process from large to small, from coarse to fine, from top to bottom. Conceptually speaking, the upper layer functions to control the lower function, the more the upper layer function is more general, the lower the more specific function. The process of functional decomposition is a process from abstract to concrete, from complex to simple. The process of functional decomposition is a process from abstract to concrete, from complex to simple. Function module can be according to the specific circumstances of large some or some small decomposition is the smallest functional module can be a program of each process, and big function module can be complete a task is a set of programs. The functional framework of the system is shown in Fig. 3.

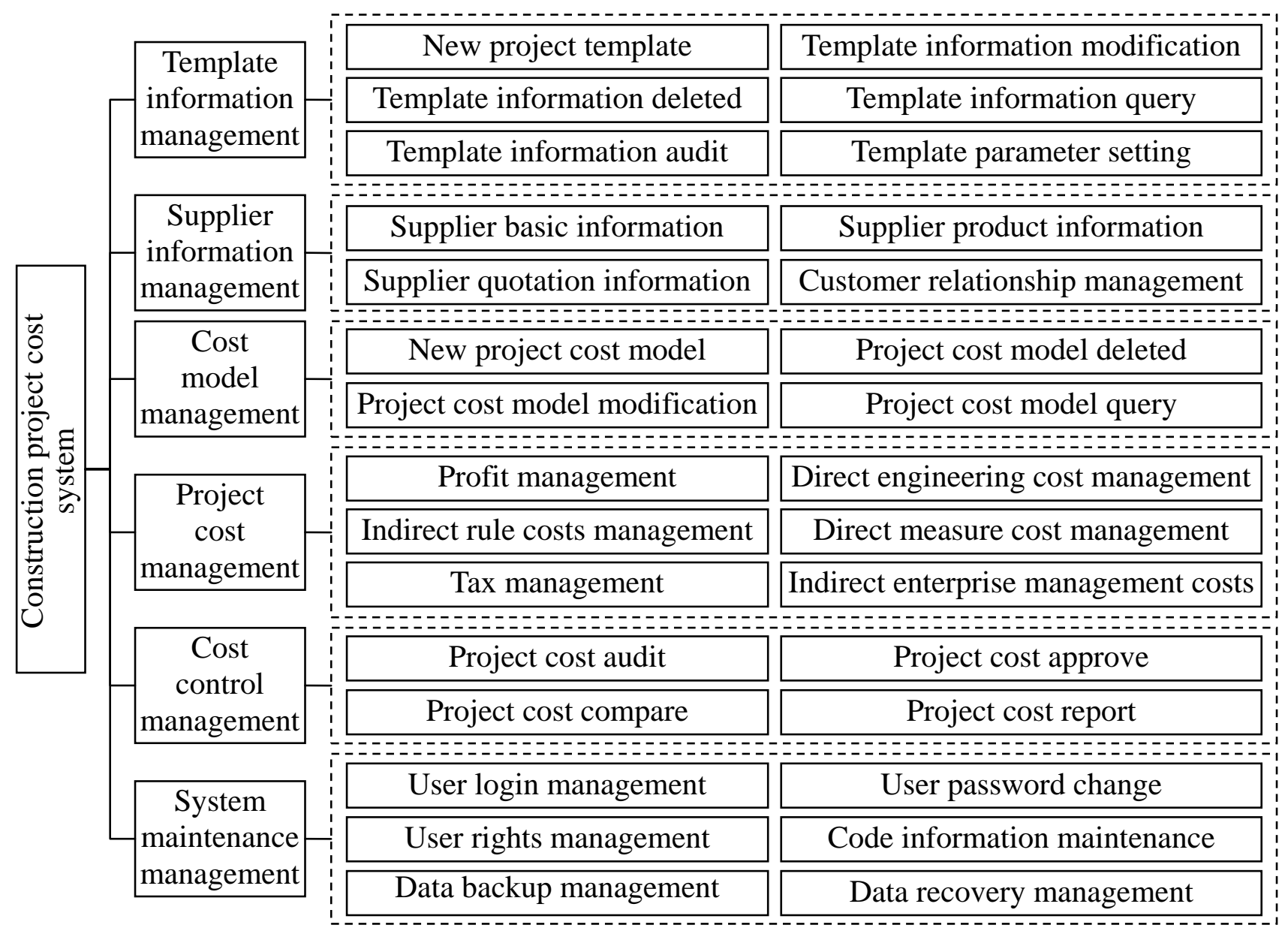

Fig. 3. Functional framework on construction project cost system

In the framework of the function shown in Figure 3,including six large modules, each module 
also includes a number of sub modules, a brief description of the following[6-8]: (1) Template information management. According to the characteristic of the construction project, designs the project cost template. Functional requirements to be able to create new cost template, query template information, modify the template, delete the template and set the parameters of the template. (2) Supplier information management. In the new building materials procurement situation, the management mechanism is the key link in the supply chain procurement management, and it has a very important role in the realization of the timely procurement. Functional aspect requirement supplier information, product information, pricing information, etc.. (3) Cost model management. A model is a formal representation of an actual problem or an objective thing, and a regular pattern. Engineering cost estimation according to the input data from the model calculation results, the need is to provide the model for the new, modify, delete and other functions. (4) Project cost management. It is the core function of the system, for the construction cost of the construction cost of the original data and the cost of management. (5) Cost control management. Management control is refers to the deviation in the business activities of enterprises in the inspection, supervision and determine the progress of the activities of the organization, appeared in the actual work and work to be corrected, so as to ensure the realization of the entire program and organizational goals. (6) System maintenance management. It provides the function of the system administrator, in order to ensure the normal operation of the system, and can respond to the system environment of the public, the information maintenance and system management, etc..

\section{Conclusion}

China's economy experiences major reform in the development process, gradually establishes a socialist market economy, people's material life and spiritual pursuit have taken place in the great changes. In the market economy environment, the construction cost management faces innovation and reform. In the project cost, cost structure and calculation methods and procedures for the project cost have a great constraint. At present, the number of Chinese construction projects is huge and the scale is also more and more large, couples with the complexity of market conditions, the construction of the limited capacity of the construction side. For the management of engineering cost is more complex, need effectively controlling the project cost and can not be controlled by a single factor. This paper studies the construction cost system function analysis, can help developers to develop powerful, economical and applicable software system, has an important role to improve the construction project cost management level.

\section{References}

[1] M. J. Huang, "On the construction cost structure and cost information management," Modern Economic Information, vol. 24, no. 14, pp. 126-127 2009.

[2] Z. W. Fu, "Discussion on construction cost structure and cost calculation," Modern Economic Information, vol. 28, no. 13, pp. 1912013.

[3] P. Wang, "Analysis on the construction cost structure and cost information management research," Technology Innovation and Application, vol. 4, no. 5, pp. 218, 2014.

[4] T. W. Zhang, S. Y. Liu, "Application Analysis," Journal of Yangtze University, vol. 3, no. 1, pp. 66-68, 2006.

[5] Zamira Daw, Rance Cleaveland, "Comparing model checkers for timed UML activity diagrams," Science of Computer Programming, vol. 111, no. 11, pp. 277-299, 2015.

[6] Krzysztof Zima, "The Case-based Reasoning Model of Cost Estimation at the Preliminary Stage of a Construction Project," Procedia Engineering, vol. 122, pp. 56-57, 2015.

[7] X. K. Wang, Y. B. Zhou, "Analysis of construction project cost project management information system," Journal of Yantai Vocational College, vol. 22, no. 2, pp. 90-92, 2015. 
[8] L. L. Xu, "Research on design and implementation of construction cost management information system," Information \& Communications, vol. 29, no. 9, pp. 117-118, 2015. 